\title{
Numerical Investigation of the Performance of Ledge Beams Considering the Contribution of Inner Stirrups to Support External Loads
}

\author{
${ }^{1}$ Mohamed O. Abd Elhady, ${ }^{2}$ Ezz El-Deen Mostafa, ${ }^{3}$ Ahmed Ghallab \\ ${ }^{1}$ Teaching Assistant, Department of Structural Engineering, Faculty of Engineering, Ain Shams University, Cairo, Egypt \\ ${ }^{2}$ Assistant Professor, Department of Structural Engineering, Faculty of Engineering, Ain Shams University, Cairo, Egypt \\ ${ }^{3}$ Professor of Concrete Structures, Department of Structural Engineering, Faculty of Engineering, Ain Shams University, Cairo, Egypt
}

\begin{abstract}
Reinforced concrete L-shaped beams are frequently used in the precast concrete industry specially in bridges construction to support a series of deck beams. The spandrel acts as a hanger for the ledge part, hence hanging reinforcement is used in the spandrel for this action. It was supposed that the outer vertical stirrups' branches are the main hanging elements for the ledge part; however, adding internal vertical branches contribute in hanging the ledge part. The perception that the outer vertical stirrups' branches solely are the main hanging elements and the neglection of the effect of inner stirrups' branches in hanging action can become questionable as it leads to using a great amount of outer reinforcement which leads to nesting of this part and increasing the fabrication cost of the beam. Therefore, a need exists to evaluate the contribution of the inner stirrups with the hanging steel reinforcement. This study aims to numerically model the performance of ledge beams taking into consideration distribution and amount of inner stirrups reinforcement, eccentricity of acting load on the capacity and performance of ledge beam.
\end{abstract}

Keywords: Shear Friction, Shear Reinforcement, Ledge Beam, Numerical modelling.

\section{INTRODUCTION}

Generally, spandrel ledge beam in bridges are used frequently to support double-tee deck beams; hence it is subjected to a series of concentrated eccentric reactions. The indirect eccentric loading combined with the unsymmetrical cross-section create a unique and complicated behaviour that must be carefully considered in design. There are three common types of spandrel beams depending upon the way the double tees are supported; spot-corbel spandrels with discontinuous ledges, L-shaped spandrels with continuous ledges and pocket spandrels with rectangular cutouts. Of these types, the L-shaped spandrel was the first to be used on a regular basis, but the next generation of longer spandrels (spanning up to $18 \mathrm{~m}$ ), often utilizes the pocket or corbel types to minimize weight, and in the case of the pocket corbel, to minimize the eccentricity of vertical loads.

\section{LITERATURE REVIEW}

Different types of failure of spandrel beam were reported (Raths[1], 1984), these types can be summarized as follows:

i. Lack of Overall Torsional Equilibrium of the Spandrel Beam

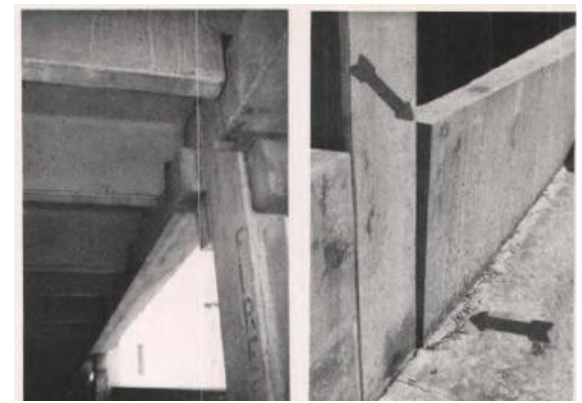

Figure 1: Lack of Overall Torsion Equilibrium (Raths[1], 1984)

ii. Failure of the Overall Torsion Equilibrium Tension Insert Connection

The non-alignment of the beam end reaction and the applied tee loads causing torsion were resisted by a horizontal couple developed by steel bolted insert tension connection near the top of the ledge and bearing of the beam web against the column top as shown in Figure 2.

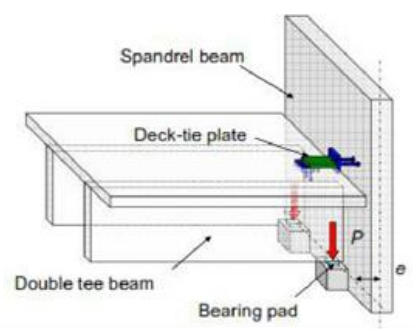

Figure 2: Overall View of Torsion Equilibrium Tension Insert Connection (Bangash[2], 2001)

iii. Beam Ledge End Corbel Failure 


\section{IRJIET}

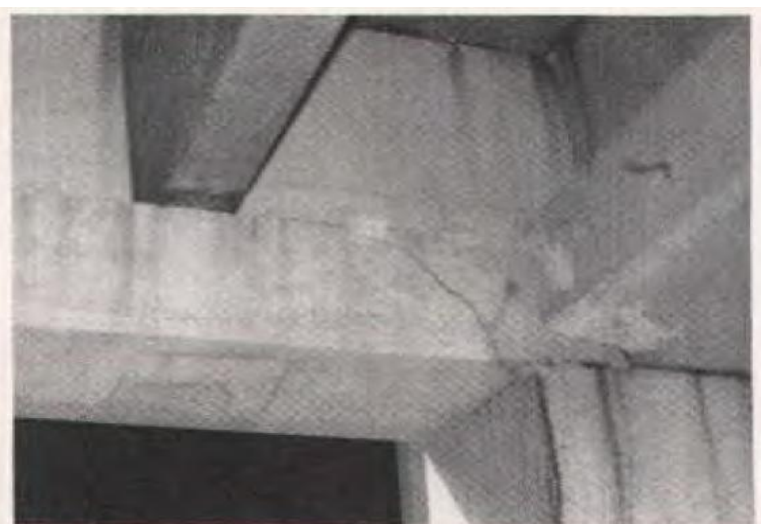

Figure 3: Beam Ledge End Corbel Failure (Raths[1], 1984)

\section{iv. Internal Spandrel Beam Torsion Distress}

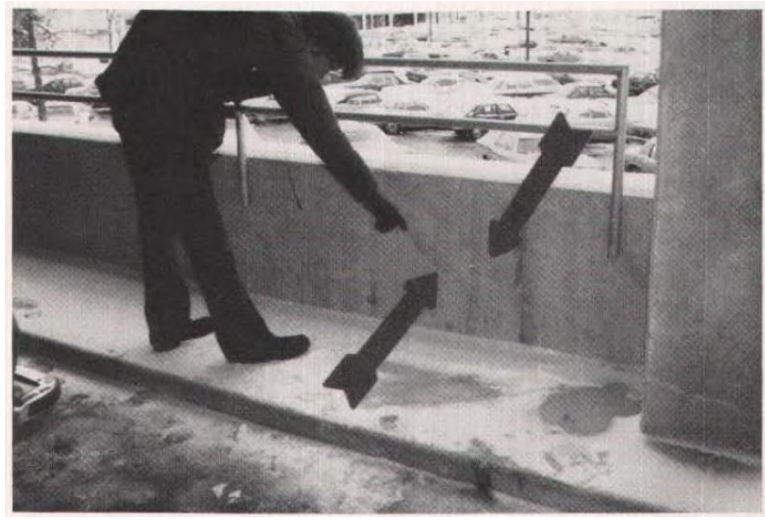

Figure 4: End Cracks due to Torsion Distress (Raths[1], 1984)

v. Complete Separation of Ledge from Web

This type of distress results from inadequate considerations of how tee reaction loads to the ledge are transmitted into the beam web.

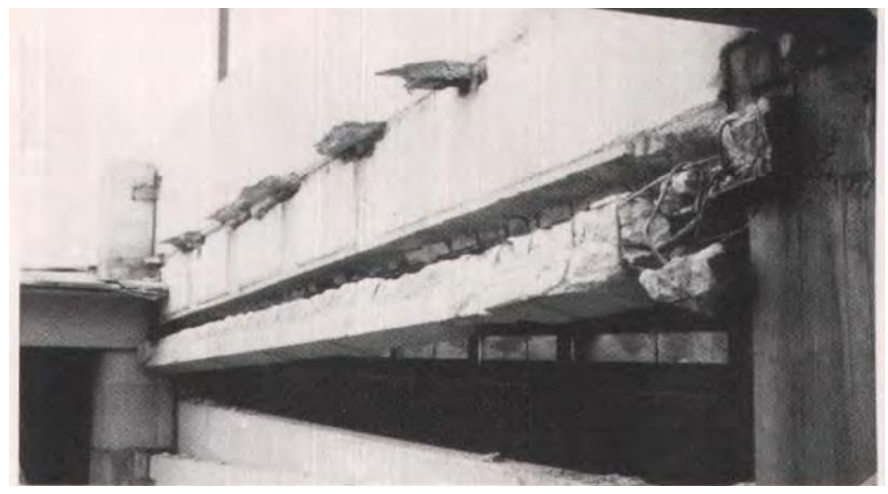

Figure 5: Complete Separation Failure of Ledge from Beam Web (Raths[1], 1984)

vi. Ledge Failure

Insufficient reinforcement at the beam end causes the concrete to act as plain concrete lacking the adequate capacity to resist applied shear and flexure forces. This is illustrated in Figure 6 as the second failure mode.

vii. Ledge Failure due to Insufficient $A_{s h}$ (Hanging Reinforcement)
ISSN (online): 2581-3048

Volume 4, Issue 6, pp 1-10, June-2020

https://doi.org/10.47001/IRJIET/2020.406001

Separation of ledge part from the spandrel occurs when the hanging reinforcement in the spandrel is insufficient to hang the ledge part.This is illustrated in Figure 6 as the fifth failure mode.

\section{viii. Punching Failure}

Load is transferred to the web through direct shear and web direct tension. As the applied concentrated loads are sufficiently high, so it might cause local punching failure under the bearing pad as shown in the sixth failure mode in Figure 6.

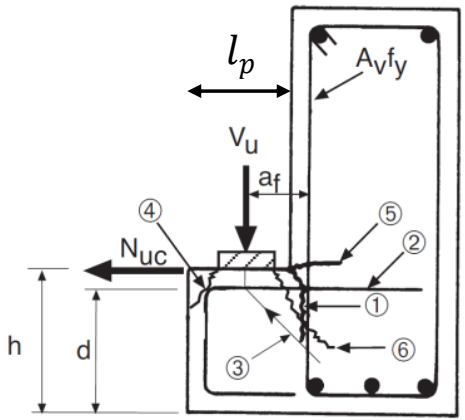

\begin{tabular}{|ll|}
\hline (1) & Shear Plane \\
(2) & Tension Tie \\
$(3)$ & Compression Strut \\
$(4)$ & Localized Bearing \\
$(5)$ & Separation \\
(6) & Punching Shear
\end{tabular}

Figure 6: Failure Modes of Beam Ledge (PCA Notes on ACI 318-11[3])

Raths (1984)[1] highlighted many aspects of the design of spandrel beams. Raths concluded that PCI Design Handbook (1978)[4] punching shear design provisions might be overestimating the punching shear capacity of spandrel beam ledges. Raths also developed two design procedures for calculating the hanging reinforcement used later by Klein(1986)[5].

Klein (1986) [5] tested three test specimens: two L-beams and one pocket spandrel. In view of the controversy regarding ledge-to-web attachment, alternate procedures were used for design of hanger reinforcement $\left(A_{s h}\right)$. For specimen (1) the hanger reinforcement was designed by Equation $A_{s h}=\frac{V_{u}}{\emptyset f_{y}}$. For specimen (2) reinforcement was designed by Equation $A_{s h}=\frac{V_{u}}{\emptyset f_{y}} * \frac{j d+a}{j d}$. Hanger reinforcement for the pocket spandrel was designed by Equation $A_{s h}=\frac{V_{u}}{\emptyset f_{y}}$, where $V_{u}$ is the ultimate shear force, $f_{y}$ is the yield strength of hanger reinforcement, $\emptyset$ is the strength reduction factor, $a$ is the distance from ledge load to center of inside face reinforcement and $j d$ is the internal moment arm. Load was applied at seven points along the beam. Regarding specimen (1), separation of ledge from web occurred. For specimen (2), punching shear failures occurred at the first and sixth tee stem from the left. For specimen (3), the ultimate failure occurred when the concrete below the fifth pocket from the left punched out. It was observed that the ledge-to-web attachment strength of specimen (1) was considerably less than predicted by Eq. 
$A_{s h}=\frac{V_{u}}{\emptyset f_{y}}$, in contrast, specimen (2) showed no sign of a ledge-to-web attachment failure, even though the test force was slightly above the capacity predicted by Eq. $A_{s h}=\frac{V_{u}}{\emptyset f_{y}} *$ $\frac{j d+a}{j d}$. The most surprising result was the punching shear failure at specimen (2). Although the ledge loads were quite high, the punching shear strength was only about 60 percent of the predicted capacity. Klein concluded that the eccentricity of the ledge load cannot be neglected in the design of hanger reinforcement, also not all of the loads acting on the ledge are suspended from the web, and the effective eccentricity of the ledge load is significantly reduced due to torsion within the ledge. Eq. $A_{s h}=\frac{V_{u}}{\emptyset f_{y}}$ may be somewhat unconservative, while Eq. $A_{s h}=\frac{V_{u}}{\emptyset f_{y}} * \frac{j d+a}{j d}$ may be overly conservative.

Hassan (2007)[6] conducted non-linear finite element analyses to model the shear/torsion behaviour of prestressed, L-shaped spandrel beams. He used Klein's second L-shaped specimen to calibrate his finite element model to demonstrate the capability of the finite element model to predict punching shear failure of spandrel ledges. Hassan studied the effect of concrete compressive strength on punching capacity and he found that increasing $\left(f_{c u}\right)$ from $40 \mathrm{MPa}$ to $60 \mathrm{MPa}$ lead to 13 percent increase in punching shear capacity. However, according to PCI Design handbook 2004 [7], this increase in concrete strength will improve the punching shear capacity by 22 percent. Hassan concluded that PCI shear design provisions for concrete ledges provided less safety factors for high strength concrete.

Also, Hassan studied the effect of increasing ledge width $\left(l_{p}\right)$ on punching capacity. Hassan found that increasing ledge width $\left(l_{p}\right)$ from $150 \mathrm{~mm}$ to $250 \mathrm{~mm}$ (66 percent increase) reduced the punching shear capacity by 10 percent. However, according to PCI Design handbook (2004)[7], a corresponding increase in punching capacity by 11 percent took place as a result of the corresponding increase in the punching surface area of the ledge, hence Hassan concluded that the PCI expressions do not account for the effect of eccentricity between the applied load and the centroid of the critical section, which could significantly reduce the punching shear capacity of the ledge.

Regarding the amount of hanger reinforcement, Hassan found that increasing the hanger reinforcement ratio by 77 percent and 177 percent, increased the punching shear capacity by 21 and 40 percent, respectively. However, PCI Design handbook (2004) [7] do not account for the effect of the amount of hanger reinforcement.

Finally, Hassan concluded that the calculated punching capacities using PCI shear design provisions overestimated those predicted using finite element analysis by an average of 60 percent.

Mostafa (2015)[8] studied the behaviour of reinforced concrete ledge beams under vertical loads acting at the ledge part at mid span through experimental and numerical approach considering the following parameters: (a) internal vertical stirrups, (b) thickness of ledge part, (c) web width, (d) eccentricity of the acting load. Mostafa concluded that the effective width at which the hanger reinforcement transverse the vertical load acting on the ledge part is (4-5) times the ledge beam depth each side from the acting load. Mostafa made a comparison between the design procedures of PCI Design Handbook (2010) [9] and PCA Notes on ACI (318-11) [3] and came to a conclusion that the design equation of the hanger steel reinforcement according to PCI Design Handbook (2010) [9], which takes a modification factor depending on the eccentricity of vertical load and the concrete dimensions of cross section, is in a good agreement with the experimental and numerical results and that the concept of adding the area of hanger steel reinforcement to the reinforcement resisting shear and torsion stresses according to PCA Notes on ACI (318-11)[3] leads to overestimating the required transverse reinforcement. According to PCI Design Handbook (2010)[9], the greater amount of the two terms (hanger or shear \& torsion reinforcement) should be chosen. The later approach is in a good agreement with the experimental and numerical results. The increase of the eccentricity of the acting vertical load on the ledge part decreases the punching failure load of the ledge beam. This effect is not included in the PCI design equation for calculating the punching shear strength of ledge beams.

Badawy (2017)[10] studied the contribution of internal vertical stirrups on the hanging action of the ledge beam considering the distribution of internal vertical stirrups. Badawy concluded that the inner stirrups can effectively be used as a hanger reinforcement to reduce the outer vertical stirrups amount and it has a considerable effect on the hanger load capacity of ledge beams.

\section{Code Quantification of Hanging Capacity}

\section{- PCI Design Handbook 2010[9]}

Hanger steel should be provided to join the ledge to the web, as shown in Figure 7. It should be noted that the hanger steel is not additive to the shear and torsion reinforcement and the larger of the two amounts should be selected. The required hanger steel can be calculated using the following equations:

$$
A_{s h}=\frac{V_{u}}{\emptyset f_{y}}(m)
$$




$$
m=\frac{\left[\left(d_{s}+a\right)-\left(3-\frac{2 h_{l}}{h}\right)\left(\frac{h_{l}}{h}\right)^{2}\left(\frac{b_{l}}{2}\right)-e \gamma_{t} \frac{\left(x^{2} y\right)_{l}}{\sum x^{2} y}\right]}{d_{s}}
$$

Where:

$m \geq 0.6$ for L-shaped beams.

$m \geq 0.4$ for Inverted-tee beams.

$x, y=$ Shorter and longer sides, respectively of the component rectangle forming the ledge and web parts of the beam.

$\gamma_{t}=0$, when closed ties are not used in the ledge.

$\gamma_{t}=1$, when closed ties are used in the ledge.

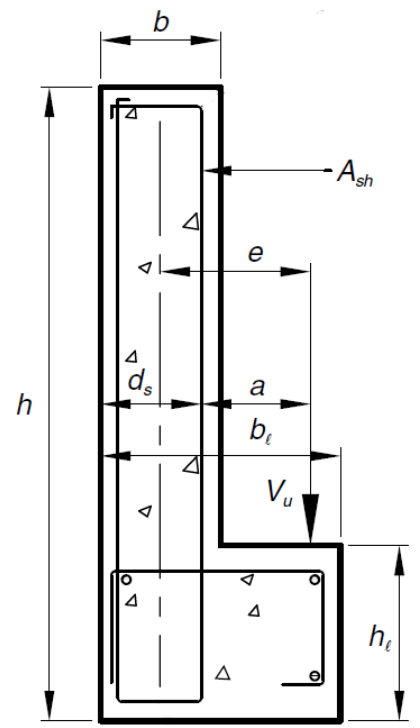

Figure 7: Ledge Hanger Steel Reinforcement Geometry (PCI Design Handbook[9], 2010)

\section{- PCA Notes on ACI 318-11[3]}

Hanger reinforcement should be proportioned to satisfy strength. Further, serviceability criteria should be considered when the ledge is subjected to a large number of live load repetitions as in parking garages and bridges. As shown in Figure 8, strength is governed by:

$$
V_{u} \leq \emptyset \frac{A_{v} f_{y}}{s} S
$$

Where:

$A_{v}=$ area of one leg of hanger reinforcement.

$S=$ distance between ledge loads.

$s \quad=$ spacing of hanger reinforcement.

Serviceability is governed by:

$$
V \leq \frac{A_{v}\left(0.5 f_{y}\right)}{s}\left(W+3 a_{v}\right)
$$

Where $(\mathrm{V})$ is the reaction due to service dead and live load.
Volume 4, Issue 6, pp 1-10, June-2020 https://doi.org/10.47001/IRJIET/2020.406001
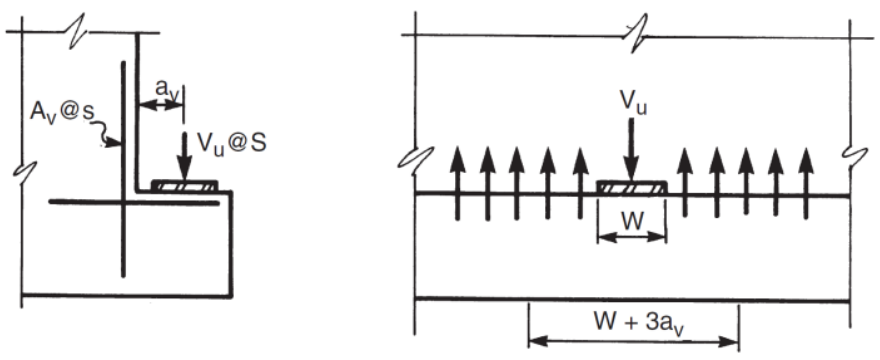

Figure 8: Hanger Reinforcement to Prevent Separation of Ledge from Stem (PCA Notes on ACI 318-11[3])

The current design procedure recommended by PCI Design Handbook 2010 [9] and PCA Notes on ACI 318-11 [3] assumes that the outer branches of vertical stirrups are resisting torsion stress and acting as a hanger for the ledge neglecting the contribution of the internal stirrups in hanging action. Therefore, the outer vertical stirrups have a great amount of reinforcement with respect to the internal stirrups. To fully understand the contribution of the internal stirrups, a 3D nonlinear finite elements model was created using ABAQUS. The accuracy of results obtained from the model were verified using results of six ledge beams selected from previous experimental work (Badawy, 2017[10]).

The followings clauses discuss the finite element model and the tested beams. Finally, a comparison between the numerical and experimental results was made to check the accuracy of the model.

\section{FINITE ELEMENT ANALYSIS}

Finite element analysis (FEA) is an extremely useful tool for numerically approximating physical structures that are too complex for regular analytical solutions. A finite element models were performed to simulate the behaviour of the tested specimens using Abaqus/CAE (Complete Abaqus Environment)[11] which is a finite element analysis software package developed by Dassault Systèmes Simulia.

\section{a) Element Types}

Two-node truss element (T3D2) with 3 degrees of freedom in every node was utilized to model steel reinforcement bars. To generate concrete beam 8-node brick element (C3D8) with three degrees of freedom in every node was considered.

\section{b) Concrete Modelling}

The concrete damaged plasticity (CDP) material model was used to model the concrete beam. This model is developed for applications in which the concrete is subjected to arbitrary loading conditions, including cyclic loading. The model takes into consideration the degradation of the elastic stiffness induced by plastic straining both in tension and 
compression. It also accounts for stiffness recovery effects under cyclic loading. This model assumes two main failure mechanisms: tensile cracking and compression crushing of concrete material.

Figure 9 and Figure 10 show the behaviour of concrete damaged plasticity model (CDP) in uni-axial tension and uniaxial compression.

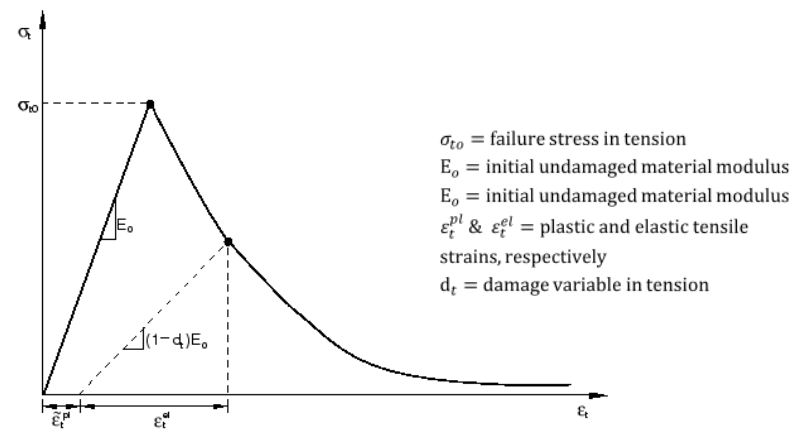

Figure 9: Uniaxial Tensile Loading in CDP

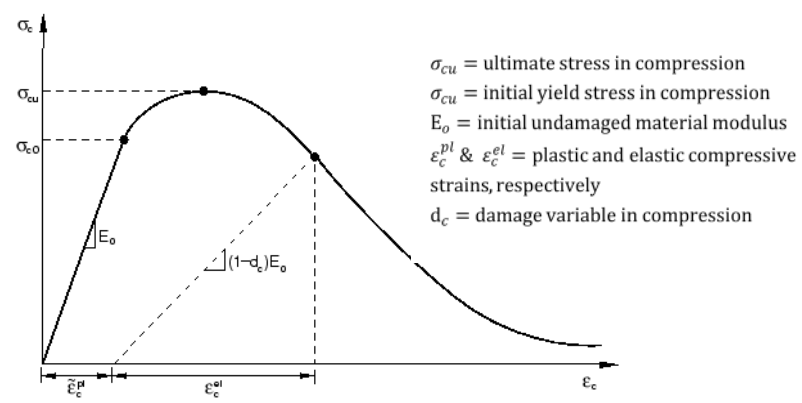

Figure 10: Uniaxial Compression Loading in CDP

\section{i. Compression Behaviour of Concrete}

As demonstrated in Figure 11, the stress-strain behaviour of concrete is simulated by using Eq. 5 proposed by Eurocode $2[12]$.

$$
\sigma_{c}=\frac{\mathrm{k} \eta-\eta^{2}}{1+(\mathrm{k}-2) \eta}\left(f_{c m}\right)
$$

Where:

$$
\begin{gathered}
\eta=\frac{\varepsilon_{c}}{\varepsilon_{c 1}} \\
\mathrm{k}=1.05 * \mathrm{E}_{c m} \frac{\varepsilon_{c}}{f_{c m}} \\
\varepsilon_{c 1}(\% 0)=0.7 *\left(f_{c m}\right)^{0.31} \leq 2.8 \\
\varepsilon_{c u 1}=0.0035
\end{gathered}
$$

The elastic modulus is calculated according to Eurocode 2

Volume 4, Issue 6, pp 1-10, June-2020 https://doi.org/10.47001/IRJIET/2020.406001

$\mathrm{E}_{c m}=22 *\left(\frac{f_{c m}}{10}\right)^{0.3}$

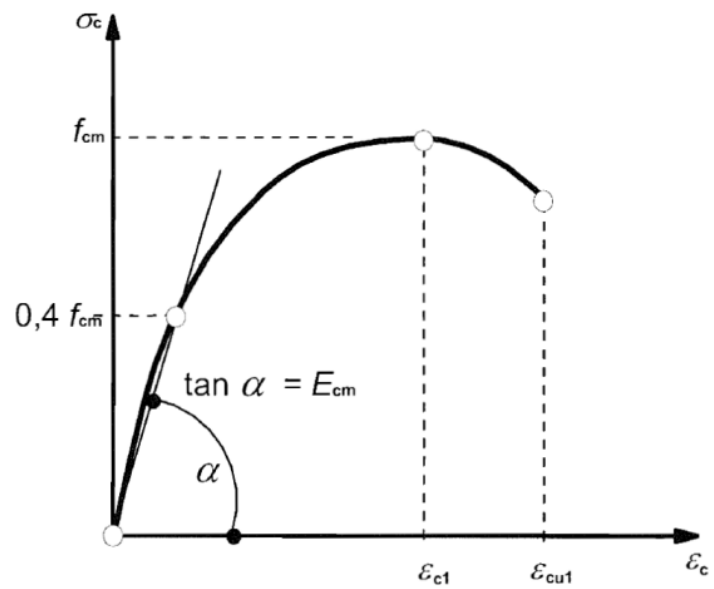

Figure 11: Eurocode Unconfined Concrete Stress-Strain Curve (Eurocode 2[12])

\section{ii. Tensile Behaviour of Concrete}

Tension model before cracking is assumed linear elastic and is defined by initial elastic modulus and by peak tensile stress. The stress strain relation for concrete in tension is proposed by Carriera and Chu (1986)[13] as Eq. 11.

$$
\sigma_{t}=\frac{\beta_{t} f_{t}\left(\frac{\varepsilon c t}{\varepsilon_{c r}}\right)}{\beta_{t}-1+\left(\frac{\varepsilon_{c t}}{\varepsilon_{c r}}\right)^{\beta_{t}}}
$$

Where,

$$
f_{t}=0.3 f_{c}^{\frac{2}{3}}
$$

$\beta_{t}$ is an empirical factor

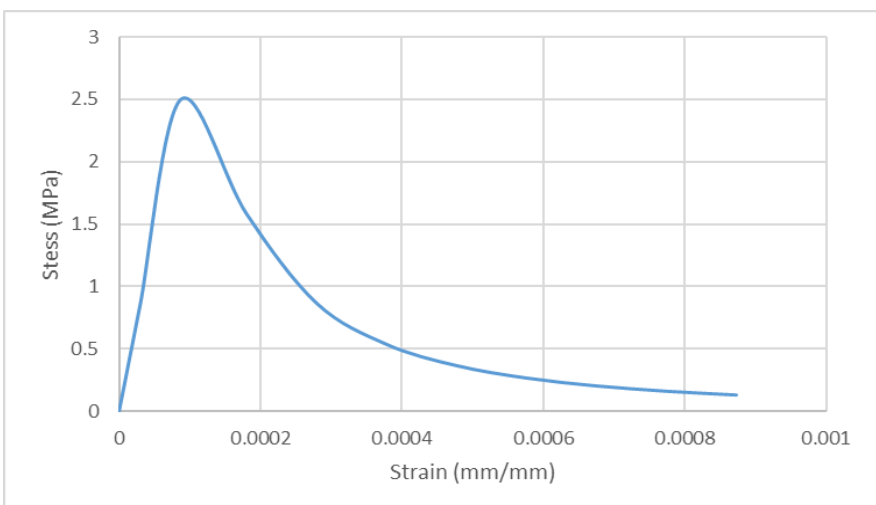

Figure 12: Uniaxial Tensile Stress-Strain Behaviour of Concrete and it's Softening Branch

Table I present the other CDP parameters which are needed to be defined in the FE software to complete the yield surface. [12]. 
TABLE I

CDP Input Parameters

\begin{tabular}{|l|l|l|l|l|l|} 
Parameters & Dilation angle & Eccentricity & fb0/fc0 & K & Viscosity \\
\hline
\end{tabular}

\begin{tabular}{|l|c|c|c|c|c|}
\hline Value & 30 & 0.1 & 1.16 & 0.67 & $1.00 \mathrm{E}-03$ \\
\hline
\end{tabular}

\section{c) Reinforcement Modelling}

The uniaxial tensile stress-strain behaviour of steel bars was considered to be elastic with $E_{s}$ and $v$. The plastic behaviour is also modelled including yield stress and corresponding plastic strain with the same behaviour (stressstrain curve) of the tested steel bars as shown in Figure 13.

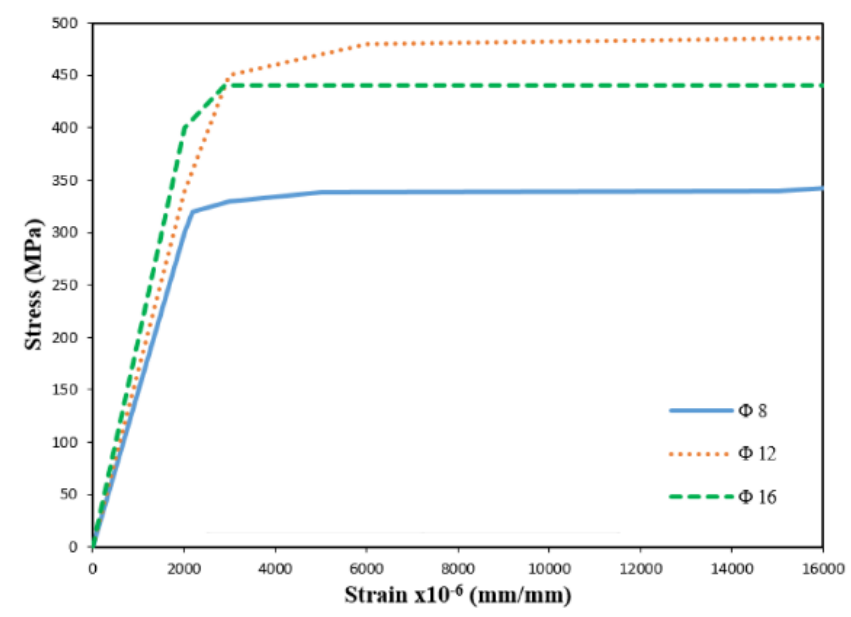

Figure 13: Stress-Strain Curve for Steel (Badawy[10], 2017)

\section{d) Boundary Conditions}

The boundary conditions in the model were specified by restraining the translation in y-direction to simulate the same action of the hinged base provided by the steel base under the tested ledge beam as shown in Figure 14.

Regarding the horizontal restrains, all nodes on the front and back of the ledge beam with the same dimension of steel plates used in the experimental program were restrained from the translation in $\mathrm{x}$-direction to restrain the torsional moment. In addition, to simulate the anchor bolts that were used to tie the front and back steel plates in the experimental program, these nodes were restrained from the translation in $\mathrm{z}$-direction as shown in Figure 15.
https://doi.org/10.47001/IRJIET/2020.406001

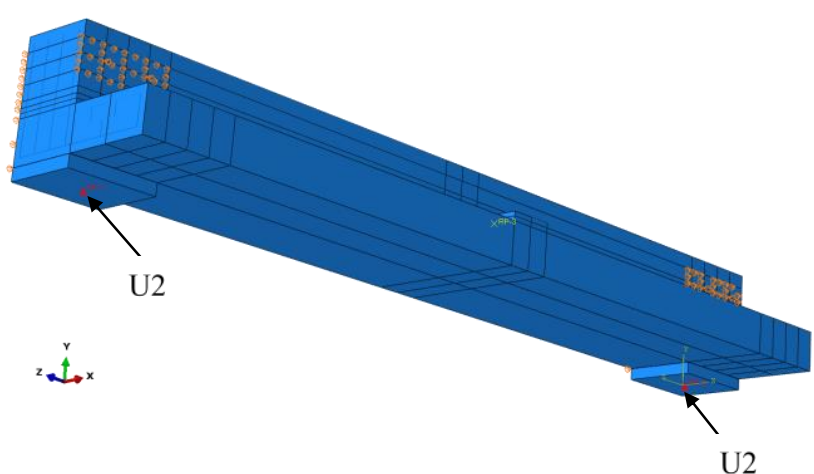

Figure 14: Vertical Restraints of Ledge Beam

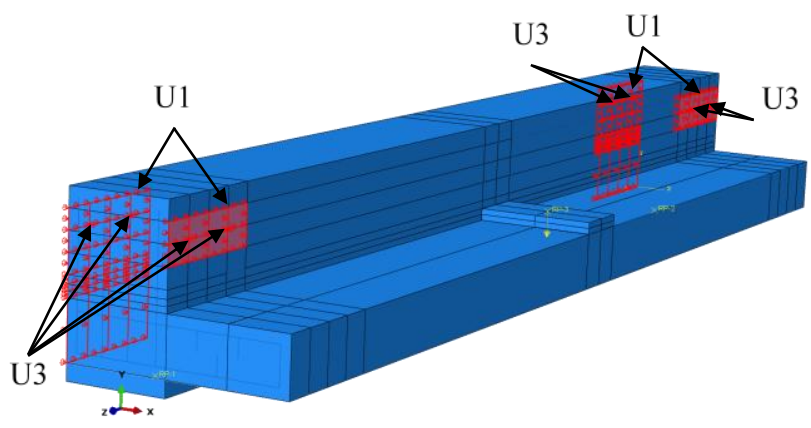

Figure 15: Horizontal Restraints of Ledge Beam

\section{e) Applied Loads}

Vertical concentrated load was applied at the middle of the beam on the top surface of the ledge as shown in Figure 16.

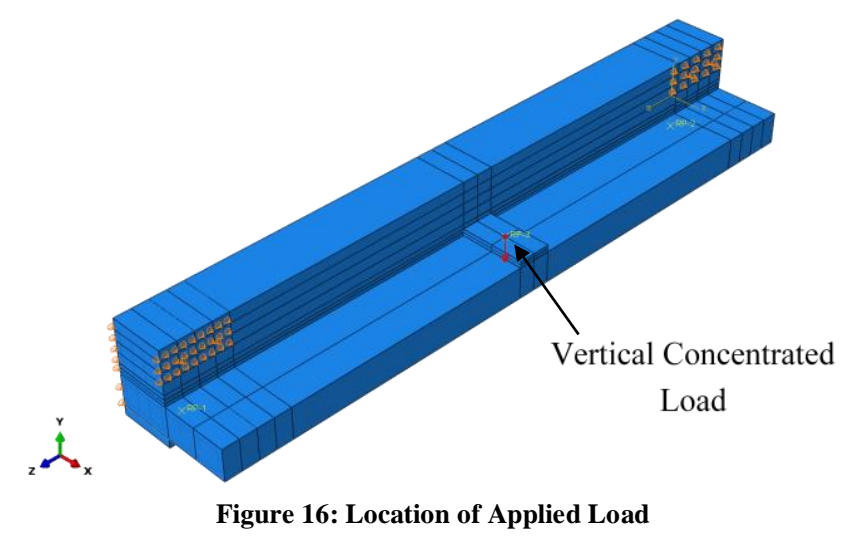

\section{VERIFICATION OF NUMERICAL MODELS WITH EXPERIMENTAL RESULTS}

In 2017, Badawy[10] tested six simply supported RC ledge beams (A1, A2, A3, A4, A5 and A6) under concentrated single load at mid-span as shown in Figure 17. The beams were $380 \mathrm{~mm}$ height, $250 \mathrm{~mm}$ web thickness and $140 \mathrm{~mm}$ ledge thickness as shown in Figure 18 to Figure 23. The variable of the tested beams (A1, A2, A3, A4) is the spacing of the inner stirrups, while for beams (A5, A6) the variable is the load eccentricity. 


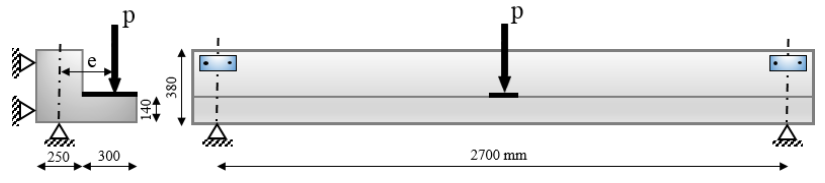

Figure 17: Statical System of Tested Specimens (Badawy[10], 2017)

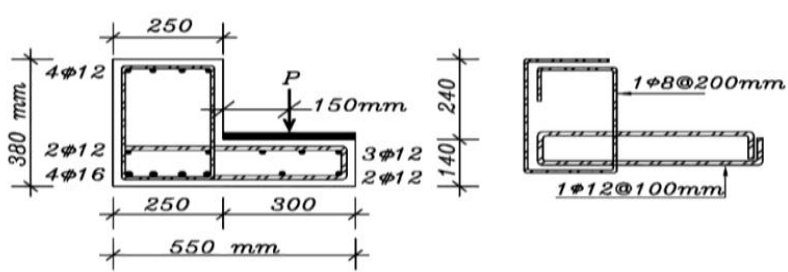

Figure 18: Concrete Dimensions and Reinforcement Details for Specimen (A1) (Badawy[10], 2017)

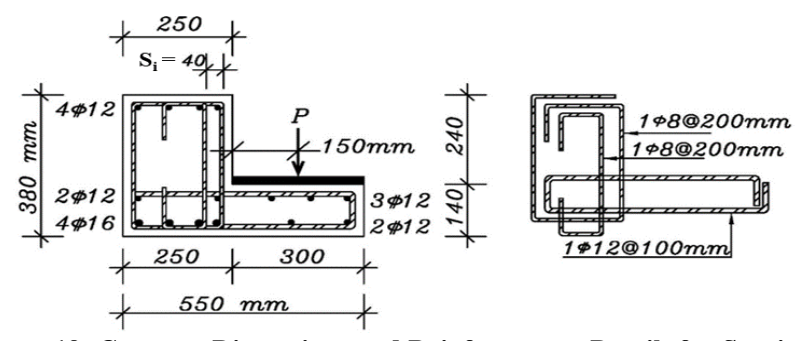

Figure 19: Concrete Dimensions and Reinforcement Details for Specimen (A2) (Badawy[10], 2017)

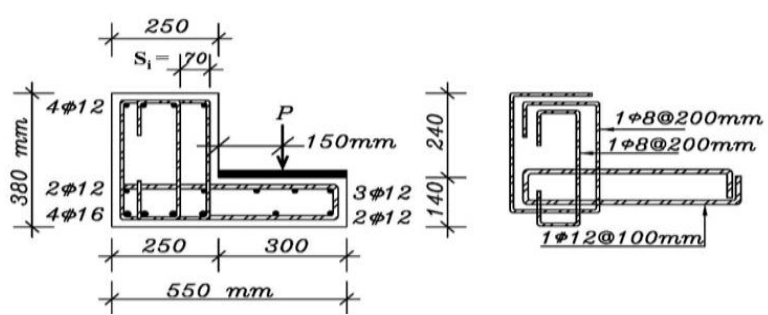

Figure 20: Concrete Dimensions and Reinforcement Details for Specimen (A3) (Badawy[10], 2017)

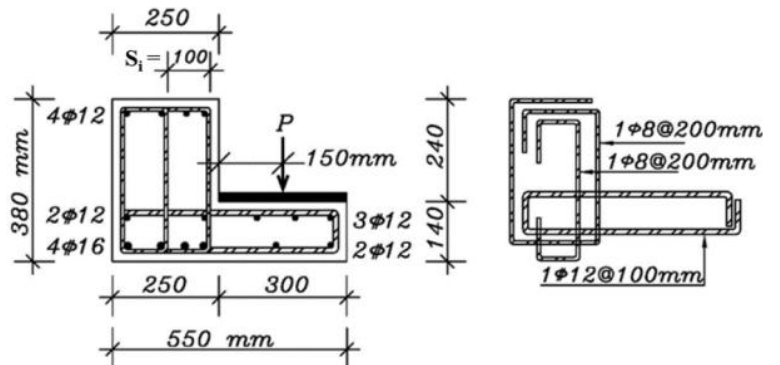

Figure 21: Concrete Dimensions and Reinforcement Details for Specimen (A4) (Badawy[10], 2017)

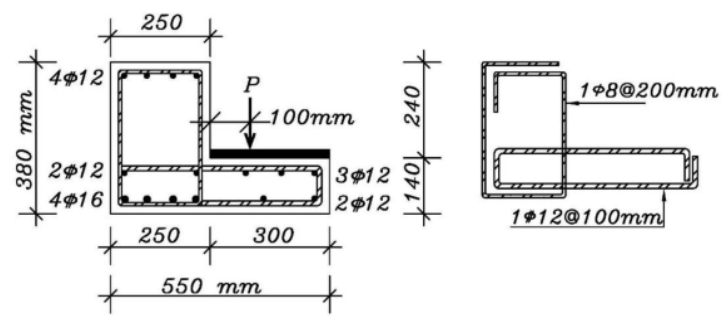

Figure 22: Concrete Dimensions and Reinforcement Details for Specimen (A5) (Badawy[10], 2017)

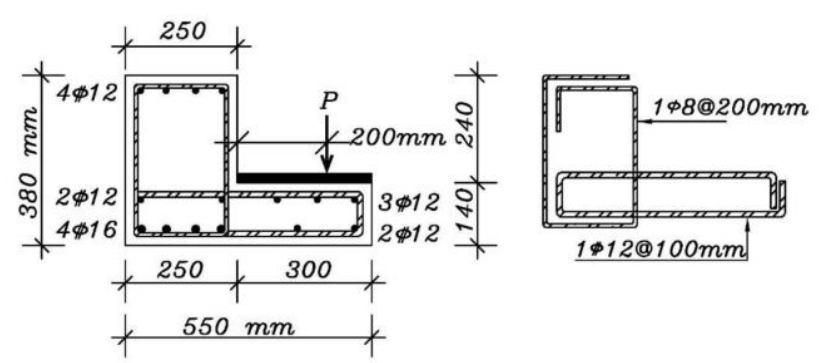

Figure 23: Concrete Dimensions and Reinforcement Details for Specimen (A6) (Badawy[10], 2017)

In order to have a reliable numerical model, the six tested beams (A1, A2, A3, A4, A5 and A6) were developed in ABAQUS[11]. The comparisons between experimental and numerical outcomes for the six mentioned models are illustrated in Figure 24 to Figure 29. These figures show the relations between the applied load and deflection at the inner and outer edge of the ledge. Failure of all beams started by yielding of hanger reinforcement and ended by load punching. As can be seen the models were capable to predict the sequence of beams' failure with high accuracy.

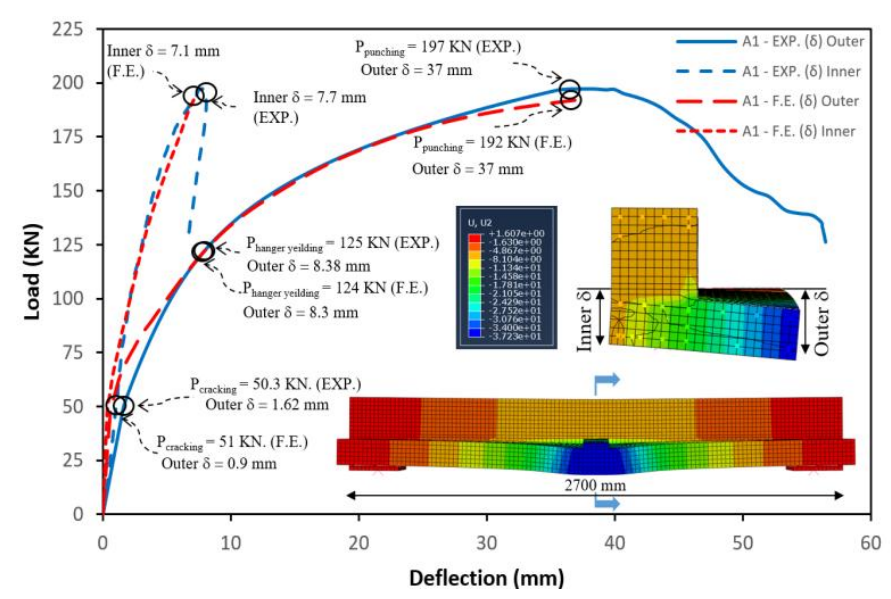

Figure 24: Load-Deflection Behaviour for Beam A1 at Midspan

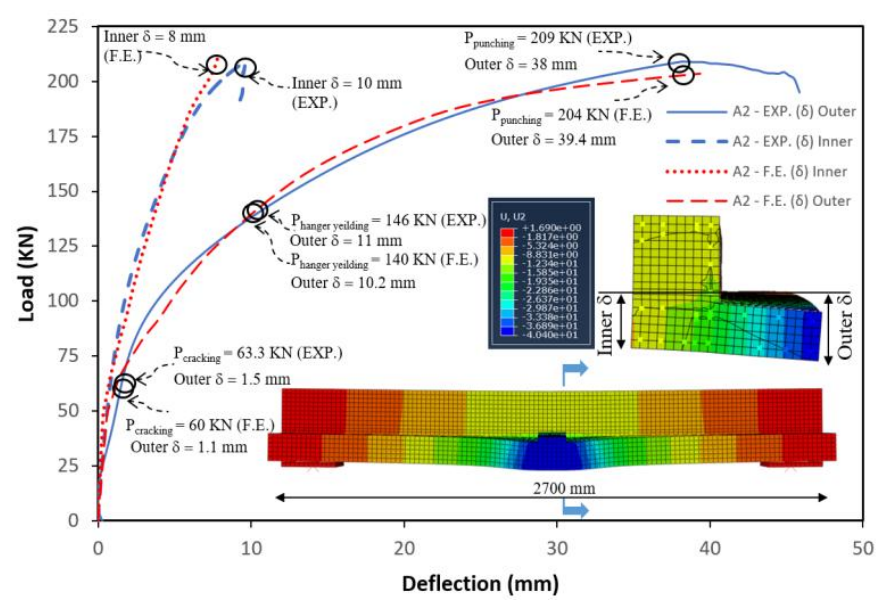

Figure 25: Load-Deflection Behaviour for Beam A2 at Midspan 


\section{IRJIET}

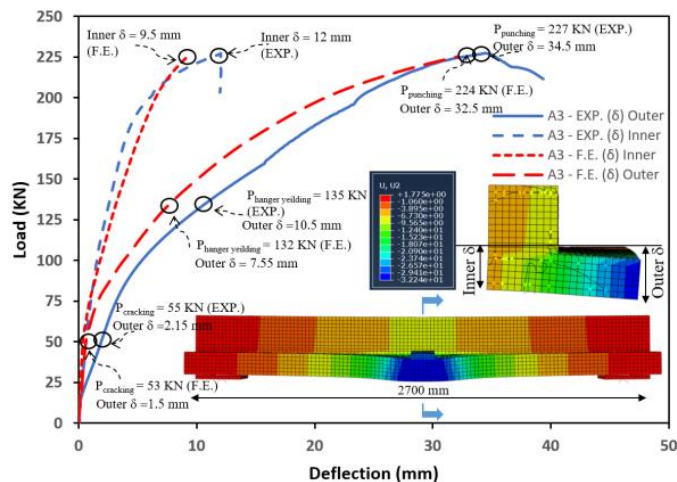

Figure 26: Load-Deflection Behaviour for Beam A3 at Midspan

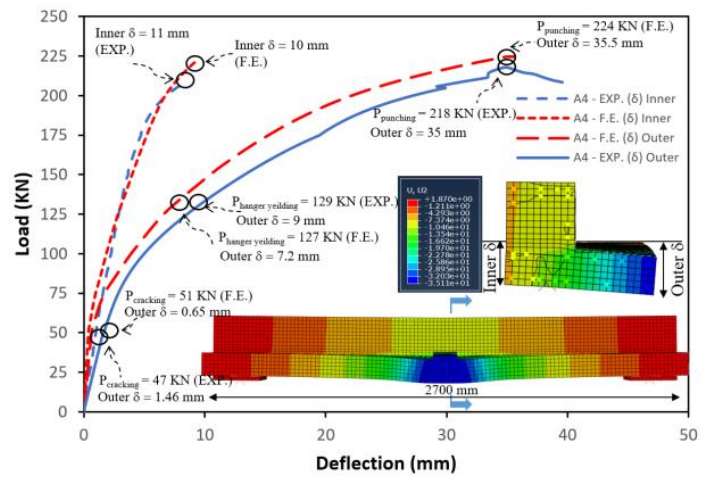

Figure 27: Load-Deflection Behaviour for Beam A4 at Midspan

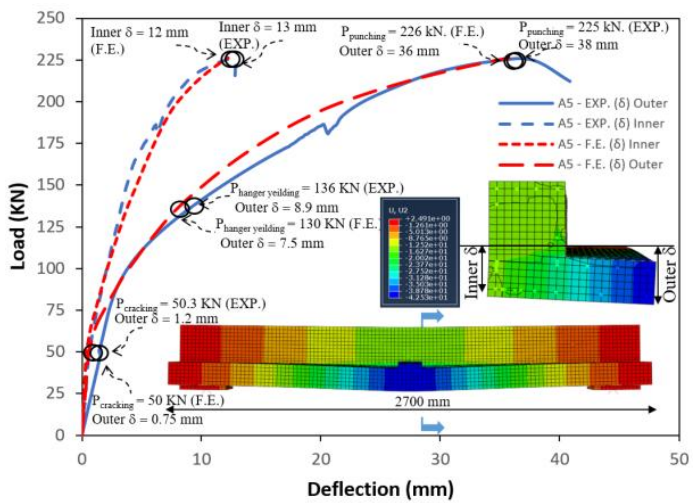

Figure 28: Load-Deflection Behaviour for Beam A5 at Midspan

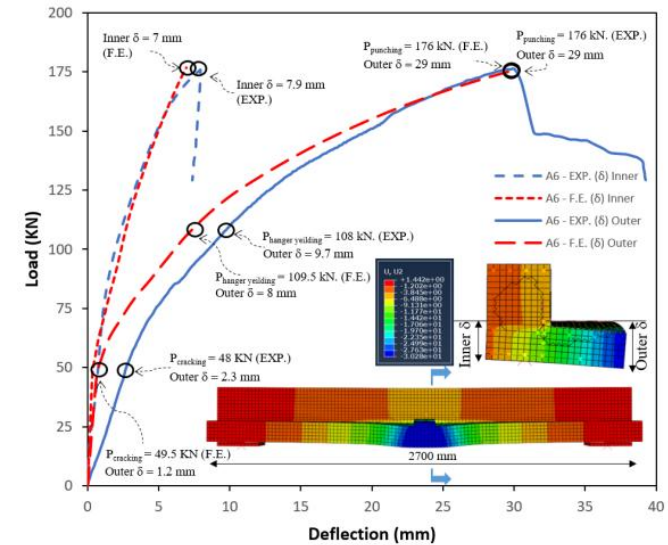

Figure 29: Load-Deflection Behaviour for Beam A6 at Midspan
ISSN (online): 2581-3048

Volume 4, Issue 6, pp 1-10, June-2020 https://doi.org/10.47001/IRJIET/2020.406001

Table II and Figures 30, 31 show a comparison between the experimental and theoretical cracking and failure loads for all beams. As shown the ratio between the experimental and the numerical results was less than $5 \%$.

TABLE II

Cracking Load, Steel Hanger and Punching Failure Loads for Exp. and F.E.

\begin{tabular}{|c|c|c|c|c|c|c|c|c|c|}
\hline \multirow[t]{2}{*}{ Specimen } & \multicolumn{2}{|c|}{ Cracking load (KN) } & \multirow{2}{*}{$\begin{array}{l}\text { Cracking load } \\
\% \text { (F.E. / Exp.) } \\
\end{array}$} & \multicolumn{2}{|c|}{$\begin{array}{l}\text { Hanger failure load } \\
(\mathrm{KN})\end{array}$} & \multirow{2}{*}{$\begin{array}{l}\text { Hanger failure } \\
\text { load } \\
\% \text { (F.E. / Exp.) }\end{array}$} & \multicolumn{2}{|c|}{$\begin{array}{l}\text { Punching failure } \\
\text { load }(\mathrm{KN})\end{array}$} & \multirow{2}{*}{$\begin{array}{l}\text { Punching } \\
\text { failure load } \\
\% \text { (F.E. / Exp.) }\end{array}$} \\
\hline & F.E. & Exp. & & F.E. & Exp. & & F.E. & Exp. & \\
\hline $\mathrm{A} 1$ & 51 & 50.3 & 101.39 & 124 & 125 & 99.20 & 192 & 197 & 97.46 \\
\hline $\mathrm{A} 2$ & 60 & 63 & 95.24 & 140 & 146 & 95.89 & 4 & 209 & 97.61 \\
\hline $\mathrm{A} 3$ & 55 & 53 & 103.77 & 132 & 135 & 97.78 & 224 & 227 & 98.68 \\
\hline $\mathrm{A} 4$ & 51 & 47 & 108.51 & 127 & 129 & 98.45 & 224 & 218 & 102.75 \\
\hline $\mathrm{A} 5$ & 50 & 50.3 & 99.40 & 130 & 136 & 95.59 & 226 & 225 & 100.44 \\
\hline $\mathrm{A} 6$ & 49.5 & 48 & 103.13 & 109.5 & 108 & 101.39 & 176 & 176 & 100.00 \\
\hline \multicolumn{3}{|c|}{ Average } & 101.91 & \multicolumn{2}{|c|}{ Average } & 98.05 & \multicolumn{2}{|c|}{ Average } & 99.49 \\
\hline \multicolumn{3}{|c|}{ Standard deviation } & 4.07 & \multicolumn{2}{|c|}{ Standard deviation } & 1.98 & \multicolumn{2}{|c|}{ Standard deviation } & 1.83 \\
\hline
\end{tabular}

Table III shows a comparison between the experimental hanger yielding load and the calculated one using PCI 2010[9] and PCA Notes on ACI 318-11[3] equations. As can be seen PCA Notes on ACI 318-11[3] equation underestimated this load at all cases while PCI equation show good agreement with the experimental results.

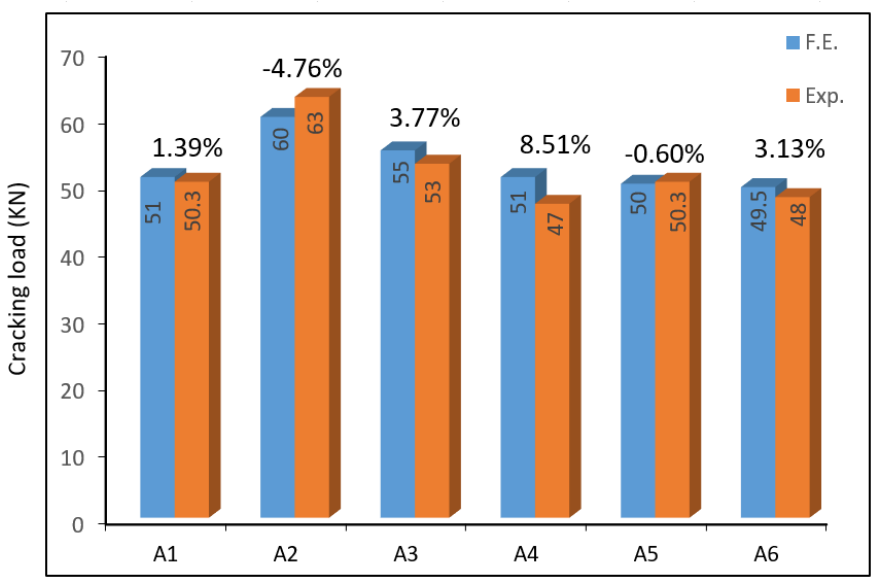

Figure 30: Experimental Versus F.E. Regarding Cracking Loads

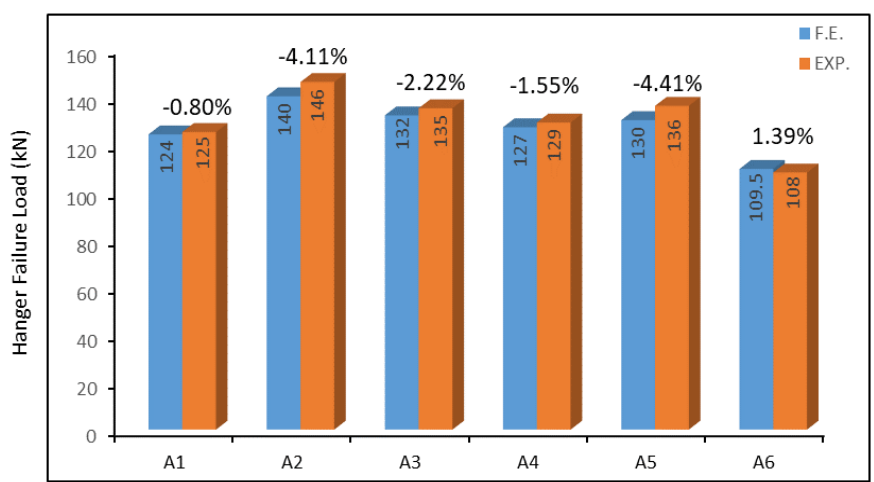

Figure 31: Experimental Versus F.E. Regarding Hanger Failure Loads 
ISSN (online): 2581-3048

Volume 4, Issue 6, pp 1-10, June-2020

TABLE III

Steel Hanger Failure Loads for Exp. and F.E.

\begin{tabular}{|c|c|c|c|c|}
\hline & $\begin{array}{c}\text { Exp. } \\
\text { Hanger } \\
\text { Specimen }\end{array}$ & $\begin{array}{c}\text { PCI } \\
\text { Hanger } \\
(\mathrm{KN})\end{array}$ & $\begin{array}{c}\text { PCA } \\
\text { Hanger } \\
\text { failure load } \\
(\mathrm{KN})\end{array}$ & $\begin{array}{c}\% \\
\text { failure load } \\
(\mathrm{KN})\end{array}$ \\
\hline A1 & 125 & 120 & 45 & $104 \%$ \\
\hline A2 & 146 & 120 & 45 & $122 \%$ \\
\hline A3 & 135 & 120 & 45 & $113 \%$ \\
\hline A4 & 129 & 120 & 45 & $108 \%$ \\
\hline A5 & 136 & 141 & 34 & $96 \%$ \\
\hline A6 & 108 & 103 & 42 & $105 \%$ \\
\hline
\end{tabular}

\section{CONCLUSIONS}

This paper presented a finite element model that prepared to study the behavior of ledge beam under different loads. The model is capable to consider the effect of distribution and amount of inner stirrups reinforcement, eccentricity of acting load on the capacity and performance of ledge beams.

Based on the experimental results and the finite element models results, the followings were obtained:

- The FEM model is considered a reliable one and could be used efficiently and with acceptable accuracy to investigate the behavior of ledge beam.

- The inner stirrups can effectively be used as a hanger reinforcement to reduce the outer vertical stirrups amount.

- The use of inner stirrups reinforcement has a considerable effect on the hanger load capacity of ledge beams.

- The concept of adding the area of hanger steel reinforcement to the reinforcement resisting shear and torsion stresses according to PCA Notes on ACI 318-11[3] leads to overestimating the required transverse reinforcement.

- According to the PCI Design Handbook (2010) [9], the greater amount of the two terms (hanger or shear $\&$ torsion reinforcement) should be chosen. The later approach is in a good agreement with the experimental and numerical results.

\section{REFERENCES}

[1] C. Raths, "Spandrel Beam Behaviour and Design," PCI Journal 29, 62-131, 1984.

[2] M. Bangash, "Manual of Numerical Methods in Concrete: Modelling and Applications Validated by Experimental and Site-Monitoring Data," T. Telford, 2001.

[3] M. Kamara, L. Novak, "PCA Notes on ACI 318-11 Building Code Requirements for Structural Concrete
[4] Precast/Prestressed Concrete Institute, "PCI Design Handbook," 2nd Edition, 1978.

[5] G. Klein, "Design of Spandrel Beams," PCI Journal 31, 76-124, 1986.

[6] T. Hassan, "Finite Element Study of Shear Behavior of Spandrel Ledges and Comparison with PCI Shear Design Provisions," Adv. Struct. Eng., vol. 10, no. 5, pp. 475-485, Oct. 2007.

[7] Precast/Prestressed Concrete Institute, "PCI Design Handbook," 6th Edition, 2004.

[8] E. Mostafa, "Effect of Hanger Steel and It's Location on the Behavior of Ledge Beam," Ain Shams University, 2015.

[9] Precast/Prestressed Concrete Institute, "PCI Design Handbook," 7th Edition, 2010.

[10] Y. Badawy, "Contribution of Inner Stirrups with the Hanger Steel Reinforcement on the Behaviour of Ledge Beam," Ain Shams University, 2017.

[11] Dassault Systèmes Simulia Corp., “Abaqus Analysis User's Guide," 2016.

[12] BS EN 1992-1-1, "Eurocode 2: Design of concrete structures, General rules and rules for buildings," 1992.

[13] D. J. Carreira and K. H. Chu, "Stress-Strain Relatonship For Reinforced Concrete In Tension," J. Am. Concr. Inst., vol. 83, no. 1, pp. 21-28, Jan. 1986.

[14] ACI Committee 318. ACI 318-19, "Building Code Requirements for Structural Concrete and Commentary," 2019.

[15] S.V. Chaudhari and M.A. Chakrabarti, "Modeling of Concrete for Nonlinear Analysis Using Finite Element Code ABAQUS" International Journal of Computer Applications (0975 - 8887) Volume 44- No.7, 2012.

[16] M. Nafadi, G. Lucier, S. Rizkalla, P. Zia, and G. Klein, "Ledge Behaviour and Strength of Long-Span L-Shaped Beams" PCI Journal 63, 50-66, 2018.

[17] M. Nafadi, O. Khalafalla, G. Lucier, S. Rizkalla, P. Zia, and G. Klein, "Ledge Behaviour and Strength of Short-Span L-Shaped Beams" PCI Journal 63, 67-86, 2018. 
ISSN (online): 2581-3048

Volume 4, Issue 6, pp 1-10, June-2020 https://doi.org/10.47001/IRJIET/2020.406001

\section{AUTHOR'S BIOGRAPHIES}

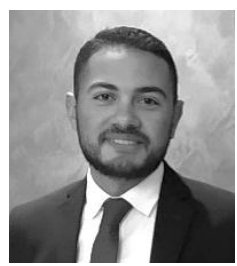

Mohamed O. Abd Elhady, is a Teaching Assistant at Department of Structural Engineering, Faculty of Engineering, Ain Shams University, Cairo, Egypt.

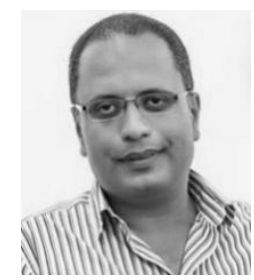

Ezz El-Deen Mostafa, is an Assistant Professor at Department of Structural Engineering, Faculty of Engineering, Ain Shams University, Cairo, Egypt.

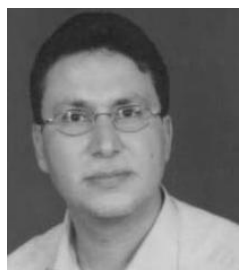

Ahmed Ghallab, is a Professor of Concrete Structures at Department of Structural Engineering, Faculty of Engineering, Ain Shams University, Cairo, Egypt.

\section{Citation of this Article:}

Mohamed O. Abd Elhady, Ezz El-Deen Mostafa, Ahmed Ghallab, "Numerical Investigation of the Performance of Ledge Beams Considering the Contribution of Inner Stirrups to Support External Loads" Published in International Research Journal of Innovations in Engineering and Technology - IRJIET, Volume 4, Issue 6, pp 1-10, June 2020. https://doi.org/10.47001/IRJIET/2020.406001 